\title{
APRENDIZAGEM COLABORATIVA: ANÁLISE DE UMA ATIVIDADE DE INGLÊS EM GRUPO
}

\author{
Magali Saddi Duarte*
}

\begin{abstract}
Resumo
O presente artigo tem como objetivo relatar o processo de colaboração observado em uma atividade de língua estrangeira - inglês, na perspectiva da abordagem sociocultural, em que a pesquisadora levanta as seguintes questóes: como os alunos adolescentes de um centro de línguas de uma escola do sistema $S$, no nível pré-intermediário, reagem à proposta de trabalho colaborativo e quais as consequências observadas a partir da interação dos alunos. PalaVras-Chave: abordagem sociocultural, aprendizagem colaborativa, interação.
\end{abstract}

\section{Collaborative Learning: analyses of an English activity in group}

\section{Abstract}

This paper aims at reporting a collaborative process observed in an English class activity, in a Sociocultural perspective. The researcher addresses the following research questions: how pre-intermediate adolescents from a language center in a Brazilian school of S system with different levels of proficiency react to the proposal of collaborative work and what are the consequences observed considering the students' interactions.

KEY WORDS: sociocultural approach, collaborative learning, interaction.

\section{INTRODUÇÃo}

A teoria sociocultural é amplamente utilizada nos projetos de pesquisas do campo da aquisição de língua materna e de língua estrangeira e/ ou segunda língua, na tentativa de apreender como a aprendizagem ocorre e como ela pode ser mais bem desenvolvida. Essa teoria, baseada principalmente nos estudos de Vygotsky e de seus colaboradores, tem como pressupostos que as atividades humanas: a) ocorrem em contextos culturais; b) são mediadas pela linguagem ou por outros sistemas simbólicos; e, por

Professora de Língua Inglesa do Centro de Ensino e Pesquisa Aplicada à Educação - Cepae/ UFG e doutoranda do Programa de Pós-Graduação da Faculdade de Educação da UFG. E-mail: magalisaddi@gmail.com 


\section{Revista Solta a Voz, v. 20, n. 2}

último, c) podem ser mais bem compreendidas quando investigadas no seu desenvolvimento histórico.

Para Vygotsky (1993), a linguagem é o instrumento mais importante, pois serve como mediadora para o desenvolvimento das funçóes psíquicas superiores. Nelas encontram-se a memória voluntária, o raciocínio dedutivo, etc.

Não se pode falar em aprendizagem colaborativa sem mencionar a teoria sociocultural, uma vez que a aprendizagem colaborativa tem como fundamentação a teoria desenvolvida pelo teórico russo, pois é ela que traz como premissa o fato de que o desenvolvimento cognitivo ocorre por meio da interação social (Vygotsky, 1993). Assim, categorias como interação, mediação, colaboração, cooperação foram sendo ampliadas e desenvolvidas a partir da teoria mencionada, fazendo com que o campo investigativo, no que concerne à aquisição de segunda língua e/ou língua estrangeira, sofresse um grande avanço. Isso gerou uma rica produção no meio acadêmico, que passou não apenas a subsidiar estratégias e técnicas de ensino de línguas, como também ampliou seu arcabouço teórico, tendo como resultado o surgimento de novas teorias. Vale lembrar que a aquisição de línguas não foi objeto de estudo de Vygotsky. No entanto, seu pensamento foi devidamente apropriado por linguistas na construção de teorias específicas dessa área.

Neste artigo tem-se como objetivo investigar a reação de alunos adolescentes de nível pré-intermediário de inglês como língua estrangeira, de um centro de línguas de escola do sistema $S$ (que dizem respeito ao SESC, SENAC, SESI) e apreender como eles reagem à proposta de desenvolver uma atividade colaborativa. A partir dessa produção, a investigação irá focalizar as consequências, em termos de avanço, advindas desse processo.

\section{FUNDAMENTAÇÃo TEÓRICA}

Um dos obstáculos com que se depara no processo de ensino e aprendizagem de uma língua é a pouca participação dos alunos, a falta de dosagem da fala do professor, que, na maioria das vezes, centraliza a aula na sua pessoa, o individualismo de uns, a timidez de outros, a desmotivação, só para citar alguns exemplos. Assim, justificam-se as pesquisas que buscam analisar e apreender como ocorre a aprendizagem de línguas estrangeiras, na tentativa de minimizar a angústia daqueles que lidam com essa área do conhecimento. 
Tomando a premissa da teoria sociocultural de que o desenvolvimento e a aprendizagem ocorrem primeiro pela sociabilidade, acredita-se que a interação em atividades de aulas de língua inglesa seja um meio pertinente de analisar o processo de aprendizagem. Conforme explicitam Swain e Lapkin (1998), os aprendizes, ao fazerem uso de procedimentos colaborativos, usam a língua como eles normalmente a usariam, isto é, como uma ferramenta mediadora na resolução de problemas. Os problemas são resolvidos por meio do diálogo interativo com outra(s) pessoa(s). Ainda de acordo com esses autores, por causa da origem social da cognição e dos processos cognitivos, a conversa espontânea tida pelos indivíduos em situações colaborativas de 'resolução de problemas' abrem uma janela para o processo intramental.

Assim, a teoria vygotskyana entende que a criança passa por três estágios de desenvolvimento cognitivo: no primeiro, a criança é regulada pelo objeto, fase em que o ambiente exerce influência sobre ela; no segundo, a criança sofre a regulação pelo outro (processo interpsicológico), isto é, ela é capaz de realizar determinadas tarefas com a ajuda de outras pessoas. E por último, a criança é regulada por ela mesma, auto-regulação (processo intrapsicológico) em que, de forma independente, desenvolve estratégias para executar as tarefas (Vygotsky, 2008). De acordo com a teoria sociointeracionista, a autorregulação ocorre por meio da colaboração. Nessa linha de raciocínio, temos o processo interpsicológico que vai gerar posteriormente o processo intrapsicológico, e aí, sim, pode-se dizer do processo de internalização que, segundo afirmam John-Steiner e Mahn (1997 apud Figueiredo, 2003, p. 128), "é simultaneamente um processo social e individual".

Outra importante contribuição de Vygotsky para a compreensão da aprendizagem e do desenvolvimento diz respeito à expressão, por ele cunhada, zona de desenvolvimento proximal (ZDP). Vygotsky (2008, p. 97) a define como

[...] a distância entre o nível de desenvolvimento real, que se costuma determinar através da solução independente de problemas, e o nível de desenvolvimento potencial, determinado através da solução de problemas sob a orientaçấo de um adulto ou em colaboração com companheiros mais capazes.

Com a compreensão do que seja a ZDP, pode-se falar do scaffolding, ou estruturas de apoio, que vem a ser o auxílio recebido pelo aprendiz para 
atingir o nível de desenvolvimento potencial. Os autores Wood, Bruner e Ross (1976, p. 90) descrevem o scaffolding como "um processo que possibilita à criança ou ao aprendiz solucionar um problema, executar uma tarefa ou alcançar um objetivo que estaria além da sua capacidade real”.

Vários estudiosos, tendo como base a zona de desenvolvimento proximal, levaram a teoria sociointeracional adiante, tornando-a mais completa e mais descritiva para a compreensáo do que acontece no processo de aprendizagem. No que diz respeito ao evento do scaffolding, por exemplo, Wertsch (1979 apud Donato, 1994) se apropria do termo e de forma mais esclarecedora descreve-o como sendo um mecanismo interpessoal de apoio dialogicamente constituído, que tem como consequência a co-construção do conhecimento e sua internalização em uma atividade compartilhada em que todos se beneficiam.

Tharp e Gallimore (1988) estabelecem a diferença entre os termos influência e assistência, considerando que ambos estão presentes no evento do scaffolding. Segundo esses autores,

[...] a influência é mais ampla, recíproca, compartilhada e pode estar presente em qualquer interaçáo, enquanto que a assistência flui do participante mais competente para o menos competente, sendo mais característica de interaçóes entre o professor e o aluno, por exemplo. (Tharp; Gallimore, 1988 apud Silva, 1999, p. 42)

Wood, Bruner e Ross (1976 apud Antón, 1999, p. 235) explicitam seis características das estruturas de apoio, ou scaffolding, que vêm a ser:

- estabelecimento ou restabelecimento de interesse pela tarefa;

- simplificação da tarefa;

- persistência na busca do objetivo;

- elucidação de aspectos importantes e as discrepâncias entre o que já foi feito e a solução ideal;

- controle e frustração durante a busca de solução de problemas;

- apresentação de uma visão idealizada do que será realizado.

Outra ferramenta que provê importante suporte na aquisição de língua estrangeira é, segundo Antón (1999), a língua materna. Sem dúvi- 
da, por meio da língua materna, numa atividade colaborativa, a unidade dialógica será desenvolvida nas estruturas de apoio, ou scaffolding. Ainda de acordo com Antón (1999), a língua materna apresenta-se como uma poderosa ferramenta de mediação semiótica entre os aprendizes e os indivíduos. Ou seja, os processos interpsicológicos e intrapsicológicos ocorrem principalmente por meio dela. Antón verificou que estudos que se voltam para o uso da língua materna apontam que os alunos a utilizam na negociação, no uso de recursos conversacionais, tais como checar confirmação, checar compreensão, repetir, perguntar, entre outros.

\section{MÉTodo}

Gravação em áudio de uma sessão de atividade colaborativa, desenvolvida por dois grupos numa sala de aula de língua inglesa em que a gravação foi transcrita. O objetivo de analisar as transcriçóes foi o de apreender os eventos de scaffolding e o uso da língua materna como mediaçáo na aquisição de língua estrangeira.

\section{Contextualização E observação}

As alunas adolescentes envolvidas neste estudo são de uma turma de nível pré-intermediário de um centro de línguas de uma escola do sistema $S$, que se localiza num bairro nobre da cidade de Goiânia. A escolha dessa escola se deu pelo fato de a pesquisadora conhecer e saber que a professora desse centro trabalha na perspectiva da aprendizagem colaborativa.

A turma em questão constitui-se de doze alunos, dos quais apenas dois são do sexo masculino. Eles têm aulas, com duração de $1 \mathrm{~h} 40 \mathrm{~m}$, duas vezes por semana. A professora comentou com os alunos sobre a minha solicitação de desenvolver uma pesquisa com eles e consultou-os sobre a possibilidade de participarem dela. Disse que precisaria de pelo menos oito alunos para formar dois grupos. Segundo relato da professora, os alunos mais fracos não se mostraram com disposição para participar. Assim, oito alunas se apresentaram e elas mesmas constituíram os grupos livremente.

Ao constituírem os dois grupos, as alunas foram informadas sobre a atividade a ser desenvolvida. A pesquisadora explicou-lhes que durante o desenvolvimento da atividade haveria um gravador sobre a mesa. Ainda, antes de iniciar a atividade, a pesquisadora perguntou-lhes se concordavam em 


\section{Revista Solta a Voz, v. 20, n. 2}

gravar uma pequena entrevista sobre a atividade desenvolvida. Como elas concordaram, o passo seguinte foi solicitar-lhes a escolha de um pseudônimo.

Durante o desenvolvimento da atividade, a pesquisadora permaneceu perto dos grupos, com o objetivo de tomar nota de alguns aspectos relevantes da interação. $\mathrm{O}$ fato de a pesquisadora decidir por acompanhar o desenvolvimento da atividade fez com que ela tivesse que desenvolver a mesma atividade com os grupos em dois momentos, destacando trinta minutos para a realização da atividade e dez para a entrevista. No entanto, o primeiro grupo gastou vinte minutos para desenvolver a tarefa e o segundo, apenas quinze.

A observação destaca algumas diferenças na tomada de decisão dos grupos. O grupo 1, por exemplo, utilizou a língua materna para realizar a negociação de sentidos, enquanto o grupo 2 procurou utilizar mais a língua-alvo, inglês, do que da língua materna. $\mathrm{O}$ grupo em questão chegou, inclusive, a perguntar se a pesquisadora gostaria que as respostas da entrevista fossem em inglês ou português.

O grupo 1 mostrou-se mais à vontade com a presença da pesquisadora do que o grupo 2, que, às vezes, sentindo-se constrangido, abaixava o tom da voz na tentativa de não ser escutado.

Por meio da observação, apreendeu-se que a timidez é um fator que pode causar uma avaliação equivocada do nível de proficiência do aluno. Por exemplo, no primeiro grupo, formado pelas alunas Sah, Poly, Jane e Mary, verificou-se a pouca participação desta última na negociaçáo. Sua voz era quase inaudível. Com o decorrer do tempo, a aluna passou a participar mais e era a única que tentava negociar usando a língua-alvo.

De acordo com observaçóes de Kleiman (2001, p. 195 ),

[...] os estudos sobre a interação mostram que as formas de expressão e de comunicação são culturalmente determinadas e que a tendência de todo falante é interpretar essas formas tanto verbais como não-verbais, segundo o significado dado em seu grupo de origem. A diferença de significado não-percebida por causa de nossa interpretação também culturalmente determinada acarreta, com freqüência, o mal-entendido e a reafirmação de estereótipos. 
A observação é pertinente para as pesquisas cujo foco seja a interação, como forma de se prevenir contra possíveis prejulgamentos, que não são dados verdadeiros em relação ao objeto de pesquisa.

\section{Atividade proposta}

O grupo de alunas recebeu um handout de uma picture story composta por 15 figuras, retirada do livro Play games with English 2, de Colin Granger, editado pela editora MacMillan e Heinemann, sem data. A tarefa consistia em que as alunas definissem a ordem correta dessas figuras e posteriormente escrevessem a história, usando o tempo verbal passado. A primeira sentença já se encontrava escrita no passado e as alunas deveriam dar sequência a ela até terminá-la.

\section{AnÁlise dos DAdos}

Para a transcrição, foram adotadas as seguintes convençôes: os nomes das participantes de pesquisa são fictícios e as convençôes de transcrição de fala para todas as participantes são:

(...) fragmento curto não-transcrito

/.../ fragmento longo náo-transcrito

[ ] reconstituição da referência pelo analista

[ ...] fragmento não transcrito

( ) reconstituição da fala pelo analista

(( )) comentário do analista

... pausa

:: alongamento da vogal na fala

/ corte brusco

MAIÚSCULAS: alteração do tom de voz com efeito de ênfase.

Foram também utilizados os seguintes sinais de pontuação: vírgula (,); ponto (.); ponto de exclamação (!); ponto de interrogação (?).

A seguir, parte da transcrição efetuada pelo grupo 1, constituído pelas seguintes alunas: Sah, Poly, Jane e Mary. A transcrição que se segue tem como objetivo analisar, no diálogo colaborativo das alunas, o uso da língua materna e os eventos de scaffolding. 
As transcriçóes em negrito foram utilizadas para ressaltar o tempo gramatical correto exigido na tarefa.

\section{Transcrição do grupo 1}

\section{EXEMPLO I}

(01) Jane: Go, go, go.

(02) Jane: He wake, woke up, him heard a noise.

(03) Poly: Pera aí só um minutinho.

(04) Jane: Get into bed.

(05) Poly: Go...

(06) Jane: No. Switch on the light. Yeah! Go upstairs. Woke up.

(07) Poly: get into bed.

(08) Jane: get into bed. Take off his dressing gown.

(09) Poly e Jane: Open the door.

(10) Jane: Open the bedroom door. Hear a noise. Put on his dressing gone.

(11) Jane: Switch off the light.

(12) Poly: Go to sleep.

(13) Jane e Poly: Go downstairs.

(14) Jane e Poly: Listen at the door.

(15) Mary: Get out ...

(16) Mary e Poly: Get out of bed.

(17) ane: Começa com...

(18) Sah: Wake up.

(19) Jane: Yeah!

(20) Poly: Depois, ele escuta o barulho.

(21) Sah: Aí põe isso aqui oh, He's

(22) Mary: switch on the light.

(23) Poly: (também acho).

(24) Poly: Depois ele para e acende a luz. 
(25) Jane: É, dá pra ver o que tava acontecendo.

(26) Poly: ah, tipo assim, achei que ele ia (...).

(27) Jane e Sah: Não.

(28) Poly: Aí ele liga a luz, né?

(29) Jane: É. Aí, he's switch on the light.

No exemplo 1, Jane tomou a liderança ao puxar o handout para si, e, ao convocar as companheiras, repetiu o verbo go três vezes. A fala de Jane evidencia a necessidade de envolver todas na execução da tarefa.

Inicialmente, as alunas usam a língua-alvo para colocar a história em ordem, mas, ao negociarem a ordem ou o sentido, elas utilizam a língua materna como suporte.

Observa-se, também, que Jane coloca as duas primeiras frases da história no passado e a seguir usa o tempo presente para as outras frases, e esse tempo vai ser o tempo todo utilizado na negociaçáo da ordem das figuras. O tempo passado só será evocado quando elas entrarem em consenso sobre a ordem da história que está correta e que devem, portanto, iniciar a escrita do texto. Contudo, a transcrição evidencia que elas só conseguiram falar o passado irregular, embora tenham escrito a história usando o tempo passado corretamente.

$\mathrm{Na}$ análise dos dados, não se observa que as alunas tivessem a preocupação com a estrutura ou com a gramática da língua-alvo, mas concentravam-se na elucidação da primeira tarefa a ser executada: colocar as figuras na ordem. E, nessa tentativa, o evento de scaffolding pode ser observado nas falas 16 e 17 quando Jane, em dúvida sobre qual seria a primeira frase, diz reticentemente: "começa com..." e recebe o apoio de Sah, que lhe completa a frase com "wake up".

$\mathrm{O}$ ato de Jane vacilar na ordem do texto faz com que elas recomecem o exercício de colocar as figuras em ordem, antes de tentar escrever a história. A atitude das alunas expressa a importância da aprendizagem colaborativa, porque ainda que Jane tenha assumido a liderança, por ser supostamente a aluna com maior proficiência, em vários momentos ela precisa da colaboração de seus pares. Isso mostra que a colaboração entre mais proficientes e menos proficientes gera benefícios para ambos os componentes. 
Observa-se, na fala 15, que as alunas consideram que a história foi colocada em ordem sem apresentar divergências entre elas. Já na fala 16, Jane, ao iniciar a frase "começa com..." e interrompê-la, mostra-se insegura quanto à figura que deve ser, precisando da ajuda de Sah, que interfere dizendo "wake up". Nota-se que, ainda que o verbo wake up tenha sido o único a ser mencionado o tempo todo no passado, a aluna não foi capaz de reproduzi-lo no tempo solicitado. Pode-se inferir, a partir das observaçóes da pesquisadora, que a pouca participação de Sah no desenvolvimento da atividade evidencia a importância de o professor propiciar mais atividades em grupo.

No que se refere ao uso da língua materna como suporte de aprendizagem de uma língua estrangeira, observa-se o seu uso logo no início da atividade, como no exemplo do turno (03): "Pera aí só um minutinho". A aluna Poly, na tentativa de se fazer participante da atividade, interfere na fala da colega que inicia o exercício, utilizando a língua-alvo. Posteriormente, as alunas continuam a atividade, reproduzindo as frases na língua-alvo e remetem-se à língua materna todas as vezes que sentem dúvida, como observado no turno (17): "Começa com...?”, quando querem checar a resposta; tal como no turno (28): "Aí ele liga a luz, né?" $\mathrm{Ou}$, se querem mostrar a resposta correta, turno (21): "Aí, póe isso aqui oh, he's...". Ao quererem checar a resposta, turno (26): "Ah, tipo assim, achei que ele ia”.

O trecho transcrito acima revela que não houve dúvidas quanto ao léxico apresentado pela atividade.

EXEMPLO 2

(01) Poly: Não, he switch on the light.

(02) Jane: Não, tem um 's' aí. Você falou.

(03) Mary: Não falô.

(04) Poly: Não falei.

(05) Jane: Tá bom, então, depois a gente vê na gravação.

(06) ((incompreensível)) 
(07) Poly: Depois que ele acendeu a luz, ele... ele? LEVANTA?

(08) Jane: Não, go downstairs.

(09) Sah: Vai logo, oh cara.

(10) Jane: TÁ, VAI.((impaciente))

(11) Poly: Será que é com ed?

(12) Mary e Jane: O quê?

(13) Poly: switch.

(14) Sah: Não, eu acho que não, porque aqui não tá.

(15) Poly: Achei tipo assim oh, achei que ele ia já ia ((incompreensível))

(16) Todas: Não ((incompreensível))

(17) Poly: woke

(18) Mary: Ah, mais aqui tá é com ed, é com ed. Ele acendeu a luz, entendeu?

(19) Poly: Não, eu sei que é no passado, eu só queria saber se é regular ou irregular.

(20) Sah: ((incompreensível)) aí depois a gente vai enumerando e depois a gente faz o texto.

(21) Sah: Aqui vai ser a primeira.

(22) Mary: Não, a primeira não, a primeira é a "A".

(23) Sah: Ah, então, a partir daqui a gente vai escrevendo.

A partir do exemplo 2, observa-se que as alunas mais integradas à atividade e mais à vontade no desempenho da tarefa começam a perceber outros detalhes que não haviam sido observados até entáo. No turno (31), a aluna Jane quer que sua colega Poly corrija a sentença "He switch on the light". Para Jane, o fato de ela estar com a frase no presente remete-a ao uso do "s" na terceira pessoa do singular. No entanto, o exercício é para ser colocado no passado, mas ambas não se dão conta de que a confusão está sendo gerada, porque, ao pronunciar a frase, Poly o faz no presente.

Em outro momento, nos turnos de números 38 a 47, o mesmo verbo que causou confusão - se se colocava "s" ou não - gera dúvida quanto à sua forma no passado. (38) "Será que é com ed?"; (39) "O quê?"; (40) "switch"; (41) "Não, eu acho que não, porque aqui não tá"; (46) "Ah, mais 
aqui tá é com ed, é com ed. Ele acendeu a luz, entendeu?”; (47) "Não, eu sei que é no passado, eu só queria saber se é regular ou irregular".

$\mathrm{Na}$ interação descrita, observa-se que todos os membros do grupo participaram, seja para negar o passado regular, seja para confirmá-lo, utilizando a língua materna como suporte do aprendizado, checando confirmação, checando compreensão, provendo explicaçóes. Enquanto Poly apresenta dúvida sobre o tipo de passado, Mary entende que a aluna tem dúvida se o tempo verbal é o passado. Observa-se aqui o quanto a interação é importante no processo de aprendizagem de uma língua, posto que as participantes refletem o uso que fazem da língua-alvo, no caso em questão, a função metacognitiva se faz presente. Além disso, o evento do scaffolding está presente na ajuda de Mary, que esclarece a dúvida de Poly sobre o verbo "switch". Mais uma vez, a interaçáo dialógica nesse segmento de falas evidencia a importância do evento scaffolding na co-construção do conhecimento.

Apesar de o texto escrito pelo grupo 1 não apresentar nenhuma dúvida quanto ao uso correto do tempo verbal requerido pela atividade, a gravação do áudio mostra que as alunas não pronunciaram os verbos regulares no passado.

Uma análise que não pode deixar de ser feita é quanto ao uso da língua materna. Ainda que as teorias mais recentes reconheçam o papel da língua como suporte para a aprendizagem de qualquer língua, é preciso haver uma dosagem desse uso. Reconhecendo a interação como meio de adquirir conhecimento na língua-alvo, há de se ressaltar que a atividade em questáo pouco utilizou o speaking e mesmo observaçóes mais sistemáticas sobre a estrutura da língua. Como não houve erro na produção escrita, infere-se que a presença da pesquisadora pode ter exercido uma interferência na produção oral das alunas, ou que as aulas tenham privilegiado mais a forma que a produção oral, por se tratar de um item gramatical importante na aquisição de língua inglesa.

No desenvolvimento da tarefa, as alunas vão se mostrando cada vez mais interessadas em terminar a atividade e obter bom êxito. A seguir, outra parte transcrita do grupo 1 será mostrada, como forma de analisar o evento de scaffolding e da língua materna em uma atividade colaborativa, que implicou numa interação que ia além do que se pedia na atividade e que se entende ser uma perspectiva altamente positiva, derivada do trabalho colaborativo. 
EXEMPLO 3

(01) Sah: Aí, eh, rapidamente abriu a porta do seu quarto. Entendeu?

Póe rapidamente.

(02) Mary: É fast.

(03) Mary: Fastly Fastly, opened the door. Não é?

(04) Poly: É.

(05) (...)

(06) Jane: Opened... (...)

(07) Mary: Cadê o artigo?

(08) Poly: Opened, go fastly, opened the door.

(09) Sah: É póe isso aí, com medo ele desceu as escadas. É.

(10) Poly: Não, mas a porta, ele abriu a porta com medo.

(11) Sah: Então tá vai, go to window.

(12) Poly: Não, He go then carefully.

(13) Jane: He carefully go.

(14) Poly: Cuidadosamente.

(15) Mary: Póe ai então cuidadosamente ele desceu as escadas.

(16) Poly: Não, vamos por aqui, como ele desceu as escadascuida dosamente, ele abriu a porta.

(17) Mary: É fica melhor.

(18) Poly: Oh, mas tipo assim, cuidadosamente ele abriu a porta com medo do que tava lá (incompreensível).

(19) Mary: Uai, mas é óbvio, se ele está com medo, ele vai ficar com medo do que ele vai ver.

(20) Poly: Não, preocupado, tipo assim... preocupado do que tava...

(21) Sah: $((\ldots))$

(22) Mary: Ah, pode ser, claro.

(23) Jane: Acho que não... (...) Acho que tem, quer ver...

(24) Sah: Acho que nem com medo, nem preocupado é a palavra certa.

(25) Mary: (...)

(26) [ risos ]

(27) Jane: Depois ele desceu as escadas. 
(28) Poly: Com medo. Como fala com medo?

(29) Sah: Com medo? Tava com medo?

(30) Mary: Estava com medo?

(31) Jane: Com medo é afraid.

(32) Sah: Então, mas com medo. [A dúvida aqui era qual o termo, em inglês, se usa para formar a expressáo com medo] Tava com medo, então, o cara.

(33) Mary: Estava com medo.

(34) Poly: O verbo só. Quer colocar o verbo, coloca, uai.

(35) Jane: Com medo.

(36) Sah: With, não? Não é with, não?

(37) Jane: é, é, acho que é.

(38) Mary: He is afraid.

(39) (...)

(40) Mary: Não, he was. He was afraid

(41) Poly: Você não corrigiu aqui, oh.

[...] 42 a 83

(84) Jane: Não é went to slept, não?

(85) Mary: Não, sleep mesmo, voltou a dormir é to sleep

(86) Poly: To sleep é dormir, quando tem o to o verbo fica no infinitivo, normal.

Logo de início, Sah, que vinha tendo uma participação muito tímida na atividade, mostra-se interessada em ajudar na tarefa e usando a língua materna diz: (01) "Aí, eh, rapidamente abriu a porta do seu quarto. Entendeu? Póe rapidamente". A inserção da palavra "rapidamente" no texto era uma criação da aluna, posto que não era necessária a sua utilização. Sah enfatiza a sua vontade de usar esse termo ao expressar-se no imperativo "póe". No turno (02), Mary expressa o termo em inglês "fast" para, logo em seguida, no turno (03), fazer uma generalização da regra do advérbio e acrescentar ao termo o sufixo "ly". Observa-se que ninguém questionou o fato de o advérbio de fast ser fast, e não fastly.

Houve uma intensa negociação na busca dos léxicos "com medo e cuidadosamente”. Nos turnos de número 28 a 31, por exemplo, há mais um exemplo de scaffolding: Poly quer que se escreva que o personagem desceu as escadas com medo. No entanto, ela não sabe o termo "com 
medo", que é fornecido por Jane e internalizado pelas outras participantes a partir daí. Toda a negociação para a aquisição do vocabulário foi feita na língua materna, e as alunas, que não sabiam o termo, passam a usá-lo, como nos turnos (38) "He is afraid" e (40) "Não, he was. He was afraid".

Nas falas 84 a 86, Jane apresenta uma dúvida: (84) "Não é went to slept, não?”. Imediatamente à formulação de sua questão, Mary e Poly intervém na explicação. Mary responde: (85) "Não, é to sleep mesmo". E Poly oferece a explicação: (86) "To sleep é dormir, quando tem o to o verbo fica no infinitivo". Dificilmente a aluna seria capaz de resolver a sua dúvida, numa resolução de tarefa, individualmente. O exemplo citado evidencia a influência da fala colaborativa na co-construção da aprendizagem. A língua materna, utilizada como uma estratégia mediadora nas suas interaçóes, foi intensamente aproveitada para dirimir dúvidas, checar compreensão, auxiliar na aquisição de vocabulário, pedir esclarecimentos, discordar de respostas, explicar itens gramaticais, sugerir alternativas.

Ao término da atividade, observa-se que as alunas não expressam nenhum conflito em relação à produção, haja vista que elas nem mesmo se propóem a fazer uma leitura do que havia sido produzido. Isso leva à reflexão de que, após a atividade colaborativa, deve-se pensar em um feedback para as alunas, como forma de mostrar o resultado da produção, tanto nos seus aspectos que positivamente foram alcançados quanto nos aspectos que não foram contemplados nem percebidos pelas participantes.

A visão das alunas, no que refere à colaboração, foi obtida por meio de entrevista. O grupo 1 reconheceu, por unanimidade, a importância do trabalho em grupo, que favorece a interação, na forma colaborativa, como meio importante de aprender uma língua estrangeira, deixando entrever que, no grupo formado por colegas, umas exercem influência sobre as outras, que preferem vivenciar a influência mais do que a assistência. De acordo com as alunas-participantes, uma tarefa desenvolvida individualmente impossibilita a checagem de dúvidas e a troca de opinióes. Além de que, numa atividade em grupo, as pessoas trabalham mais dinamicamente. Ressaltaram a importância de o grupo ser formado por pessoas colaborativas e participativas de uma maneira mais homogênea e, por fim, destacaram a insatisfação de trabalhar em grupo com pessoas com as quais não têm afinidades. 
O grupo 2, que teve como participantes as alunas Tina, Ju, Gaby e Sarah, mostrou-se mais familiarizado com a língua inglesa do que o primeiro. Isso foi observado, logo de início, no exemplo 4 , na primeira tentativa de ordenar as figuras, quando no turno (02) a aluna Gaby utiliza o linking word "then" para retomar a frase do turno (01), que havia sido produzida na língua materna.

O grupo em questão, apesar de usar mais a língua-alvo e produzir os verbos no tempo solicitado (passado simples) de forma mais sistemática, em muitos momentos deixa de usar o verbo regular no passado. Isso não se configura como ausência de conhecimento, tanto que a aluna Gaby, sem se dar conta de que quase $50 \%$ da produção havia sido feita no tempo requerido, se expressa: (15) "Agora só tá faltando colocar os verbos no passado", ao que a colega Ju responde: (16) "Nossa! A gente esqueceu disso". O grupo, que até então vinha falando na língua-alvo, faz a mudança de código; neste caso, a mudança se dá para a língua materna, para guiar a ação na execução da tarefa.

Conforme Mello (2002 apud Cândido Jr., 2006, p. 49), a alternância de línguas, que se observa em aulas de língua estrangeira, ocorre justamente com o intuito de negociar os sentidos das mensagens veiculadas pelos aprendizes e suas participaçóes no processo interacional. No exemplo em análise, turno (01) "Aqui, ele acorda" e (02) "Then, he woke up", foi a mudança de código, no início da tarefa, que determinou o maior uso da língua-alvo.

EXEMPLO 4

\section{Transcrição do grupo 2}

(01) Gaby: Aqui, ele acorda.

(02) Sarah: Then, he woke up.

(03) Sarah: Then, he heard a noise. Éh, he opened, opened the door. So...

(04) Todas juntas: He opened the door.

(05) Sarah: Opened the door? No.

(06) Sarah: No.

(07) Gaby: Opened the bedroom door.

(08) Gaby: Go downstairs. 
(09) Sarah: And listen to the door.

(10) Gaby: Open the door.

(11) Tina: Open the door.

(12) Ju: See a cat outside the window. Go, go upstairs.

(13) Sarah: Éh, take off his dressing gown.

(14) Gaby: Get into bed and go switch on the light.

(15) Gaby: Agora so tá faltando colocar os verbos no passado.

(16) Ju: Nossa, a gente esqueceu disso!

No exemplo 5, do grupo 2, a língua materna vai ser usada como uma ferramenta mediadora para confirmar hipóteses (22) "é, get out of bed", (25) "ê". Para sanar dúvidas (24) "put fica no passado assim mesmo?"; (31) "Switched, é ed, no passado, não é? Thank you.". Para corrigir (20) "Primeiro ele ligou a luz. He switched on the light".

EXEMPLO 5

(17) Sarah e Gaby: Frank woke up, He heard a noise. Eh, and he switched.

(18) Ju: Não..., pode falar...

(19) Gaby: He put on.

(20) Sarah: Primeiro ele ligou a luz. He switched on the light.

(21) Gaby: Ah, éh, then He got out.

(22) Tina: É get out of bed.

(23) Sarah: Then, put.

(24) Ju: Put fica no passado assim mesmo?

(25) Sarah: É...

(26) Sarah: And he opened ...

(27) Gaby: So, he switch the light.

(28) Sarah: Then, he switch on the light.

(29) Gaby: Get out of the bed.

(30) Ju: E put on his dressing gown ... Aí...

(31) Gaby: Switched, é ed, no passado, não é? Thank you.

(32) Gaby: Tá falhando essa caneta tá? Essa aqui também ta falhando. Acho que sou eu.

(33) Sarah: Credo, suas canetas..., falha tudo. 


\section{Revista Solta a Voz, v. 20, n. 2}

Ao terminar a tarefa, a líder do grupo propôs que cada uma lesse duas frases do texto, na sequência. Nessa atividade, ninguém se dispóe a corrigir os erros produzidos pelas colegas, demonstrando, com isso, total acordo com a produção realizada. As alunas não perceberam que elas escreveram todas as frases omitindo o sujeito Frank ou "he", como se esperava que elas fizessem. Outros erros são cometidos sem que elas percebam ou corrijam, por exemplo, na leitura da aluna Ju, onde estava escrito "Saio a cat outside the window", ela leu "say a cat outside de window". Então, nessa produção não só a líder equivocou-se com o verbo, como também a colega que participava da atividade, apesar de que, no momento em que elas colocavam as frases na ordem, esse verbo foi falado corretamente "saw". A aluna Ju, ao ler, não comenta o fato de o verbo estar escrito em português, com um significado que não dizia respeito à figura da tarefa; no entanto, ela lê como se estivesse em inglês, não usa o verbo correto, que seria "saw", e, por sua vez, também não sofre a correção por parte de suas colegas.

Com exceção do verbo "see", como observado acima, todos os demais verbos foram colocados no passado corretamente na forma escrita. $\mathrm{Na}$ transcrição da parte oral, observam-se na transcrição em negrito os momentos em que os verbos foram colocados no tempo solicitado. Além disso, as alunas foram capazes de utilizar linking words tais como then, so e and.

A entrevista com o grupo mostrou que uma participante prefere trabalhar individualmente. Para Gaby, a participação de todos em trabalho coletivo é fundamental. Ao ser interrogada sobre o que ela achou da atividade, respondeu: "Eu achei legal, mas eu sou um tipo de pessoa bastante individualista, sabe? Aí, o problema que tem em grupo é porque nem todo mundo colabora. No nosso, todo mundo colaborou. Então, é assim, eu gosto muito de fazer as coisas sozinha”. A aluna analisa que, embora a atividade em grupo favoreça o aprendizado da língua inglesa, em uma atividade escrita, ela prefere o trabalho individual.

A aluna Ju avaliou que o trabalho em grupo a favorece, porque ela é muito tímida e não sabe tanto quanto as colegas. No entendimento da aluna, o trabalho em pares a favorece, porque lhe permite não só aprender o que ela não sabe como também fazer perguntas sobre as dúvidas existentes.

A aluna Sarah falou de sua preferência pelo trabalho em grupo, desde que este seja formado por pessoas que lhe sejam familiares. Caso contrário, ela prefere o trabalho individual. 
Tina, ao ser questionada se ela acha que o trabalho em grupo favorece ou não a aprendizagem de uma língua, responde o seguinte: "Favorece porque, quando a gente tem um grupo, a gente discute bastante. Conversando a gente aprende mais do que escrevendo, tem pronúncia, se você erra alguma coisa, o colega acaba corrigindo a gente, quando a gente tá sozinha, não tem como."

As informaçôes obtidas com as entrevistas permitiram verificar que as participantes de ambos os grupos preferem trabalhar com colegas com os quais têm afinidade. Daí a importância de os professores estarem atentos quando delimitam tarefas em pares. É preciso considerar que a possibilidade de uma produção mais desejável seja efetivada a partir de algo que não descontente os alunos. É preciso ainda perceber que uma atividade como a aqui descrita implica mais barulho do que é o costume em sala de aula. Contudo, há de se analisar se o barulho foi provocado pelas negociaçóes que estavam sendo feitas, ou se por motivos alheios à atividade proposta. Uma visão global desses dados aponta para o fato de que nem todos os alunos participam igualmente do desenvolvimento da atividade, o que causa contragosto aos alunos que trabalham. Esse dado pode revelar a falta de hábito de trabalhos em grupo, ou a necessidade de se desenvolver mais esse tipo de atividade como forma de levar o aluno a ser mais participativo e colaborativo. Isso porque, numa perspectiva sociointeracionista, a interação entre pares provoca o desenvolvimento e a aprendizagem, haja vista as formas de regulação descritas por essa teoria, que culminam na internalização.

\section{Algumas CONSIDERAÇÓES}

Este estudo comprova a importância do desenvolvimento de atividades em colaboração, pois os alunos se ajudam mutuamente, promovendo, dessa forma, a construção do conhecimento, além de desenvolverem a habilidade de solucionar problemas na execução de tarefas e aprenderem a compartilhar os conflitos que envolvem a aquisição de uma língua estrangeira.

A atividade, além de interessante e desejável para alunos adolescentes, quando bem orientada e supervisionada propicia a exploração das quatro habilidades em língua inglesa: listening, speaking, reading e writing. 
Verificou-se, por meio deste estudo, que a língua materna, anteriormente condenada por algumas abordagens e métodos de ensino de línguas, tais como o Método Direto e a abordagem behaviorista, possibilitou o evento de scaffolding, que contribui na ordenação da história, no entendimento do tempo verbal, na aquisição de vocabulário e na execução da tarefa de uma forma mais prazerosa, conforme respostas dadas por meio das entrevistas.

\section{REFERÊNCIAS}

ANTÓN, M. Socio-Cognitive Functions of L1 Collaborative Interaction in the L2 Classroom. The Modern Language Journal, v. 83, n. 2, p. 233247, 1999.

CÂNDIDO JR., A. Os Processos de Colaboração e de Negociação Durante a Realização de Atividades Comunicativas. In: FIGUEIREDO. F. J. Q. de (org.). A Aprendizagem Colaborativa de Linguas. Editora UFG, 2006. p. 47-80.

DONATO, R. Collective Scaffolding in Second Language Learning. In: LANTOLF, J.; APPEL, G. (edts). Vygotskian Approaches to Second Language Research. New Jersey: Ablex Publishing, 1994, p. 33-56.

FIGUEIREDO, F. J. Q. de. A Aprendizagem Colaborativa: foco no processo de correção dialogada. In: LEFFA, V. J. (org.). A interação na aprendizagem das linguas. Pelotas, RS: EDUCAT, 2003, p. 125-157.

A Aprendizagem Colaborativa de Línguas: Algumas Consideraçôes Conceituais e Terminológicas. In: FIGUEIREDO, F. J. Q. de. (org.). A Aprendizagem Colaborativa de Linguas Goiânia: Editora UFG, 2006. p. 11-45.

GRANGER, C. Play Games with English 2. MacMillan e Heinemann, (s.d.).

KLEIMAN, A. B. O Papel da Análise da Interação no Contexto de Formação da Alfabetizadora: Respostas Prontas, Perguntas Por Fazer. In: KLEIMAN, A. B.; SIGNORINI, I. (orgs.). O Ensino e a Formação do Professor. São Paulo: Artmed, 2001, p. 193-209.

SILVA, M. I. da. Uma Análise de Uma Atividade Em Sala de Aula de Língua Inglesa Numa Perspectiva Interacionista. MOARA - Revista dos Cursos de Pós-Graduação em Letras da UFPA, Belém, n. 11, p. 39-51, 1999. 
SWAIN, M.; LAPKIN, S. Interaction and Second Language Learning: Two Adolescent French Immersion Students Working Together. The Modern Language Journal, v. 82, n. 3, p. 320-337, 1998.

VYGOTSKY, L. S. Pensamento e Linguagem. Tradução Jefferson Luiz Camargo. São Paulo: Martins Fontes, 1993.

- A Formação Social da Mente. São Paulo: Martins Fontes, 2008.

WOOD, D.; BRUNER, J.; ROSS, G. The Role of Tutoring in Problem Solving. Journal of Child Psychology and Psychiatry, v. 17, p. 89-100, 1976.

Recebido em: 24 mar. 2009 Aceito em: 4 ago.2009 